\title{
Effect of Aspirin on Fractalkine in Rats with Pulmonary Embolism
}

\section{Ling-Cong Wang ${ }^{1 *}$, Jian-Nong $\mathrm{Wu}^{1}$, Guo-Lian Xia ${ }^{1}$, Wei-Mao ${ }^{1}$, Rong-Biao Ying2, Li-Quan Huang ${ }^{1}$ and Rong-Lin Jiang ${ }^{1}$}

${ }^{1}$ Department Intensive Care Unit, The First Affiliated Hospital of Zhejiang Chinese Medical University, Hangzhou 310006, ${ }^{2}$ Department of Surgical Oncology, Tumor Hospital of Taizhou, Wenling 317502, China

*For correspondence: Email: w/c501@126.com

\begin{abstract}
Purpose: To investigate the effect of aspirin on fractalkine (FKN) in rats with pulmonary embolism (PE). Methods: Sprague Dawley rats were divided into control group, sham operation group, PE model group and PE + aspirin group. PE was established by injecting self-embolus into the right jugular vein of the rats. Aspirin was administered orally 1 day and 40 min before PE surgery, and daily thereafter. At 4 and $72 \mathrm{~h}$ following embolism, the rat lung tissues were obtained for hematoxylin-eosin (HE) staining as well as measurement of mRNA expression of FKN, TNF- $\alpha$ and IL-1 . Additionally, serum $F K N, I L-8, T N F-\alpha$, and IL-1 $\beta$ were measured by enzyme linked immunosorbent assay (ELISA).

Results: The serum levels of FKN, IL-8, TNF- $\alpha$ and IL-1 $\beta$ were significantly decreased by treatment with aspirin compared with the PE group $(p<0.05)$. Furthermore, mRNA expressions of lung FKN, TNF$\alpha$ and IL-1 $\beta$ in PE group were markedly decreased by treatment with aspirin compared with that in PE group. PE-induced lung injury was alleviated by treatment with aspirin based on the results of pathological examination..

Conclusion: Aspirin has protective effects against PE-induced lung injuries, which is probably mediated by the suppression of the expression of IL-8, TNF- $\alpha, I L-1 \beta$, and FKN.
\end{abstract}

Keywords: Aspirin, Pulmonary embolism, Lung injury, Fractalkine.

Tropical Journal of Pharmaceutical Research is indexed by Science Citation Index (SciSearch), Scopus, International Pharmaceutical Abstract, Chemical Abstracts, Embase, Index Copernicus, EBSCO, African Index Medicus, JournalSeek, Journal Citation Reports/Science Edition, Directory of Open Access Journals (DOAJ), African Journal Online, Bioline International, Open-J-Gate and Pharmacy Abstracts

\section{INTRODUCTION}

Pulmonary embolism (PE) is a serious, lifethreatening disease, and is most commonly derived from deep vein thrombosis (DVT) of the lower extremities [1]. Several previous studies have demonstrated that cascade reactions of inflammation are associated with $P E$ in the lung $[2,3]$. FKN is one of the chemokines discovered in 1997, contains 373 amino acid residues and has adhesive and chemotactic activities. FKN, the only member of $\mathrm{CX} 3 \mathrm{C}$ family, is widely distributed in lung, heart, brain, kidney, pancreas and skeletal muscles [4] and plays an important role in vascular inflammation and endothelial cell injury by binding to its specific receptor CX3CR1 [5].

Our previous study found that TNF- $\alpha$ upregulates mRNA and protein expressions of FKN in human umbilical vein endothelial cells (HUVEC), and that curcuma had certain precautionary and therapeutic effects on PE rats $[6,7]$. Recently, it was suggested that aspirin effectively reduces inflammation after PE [8] and prevents the recurrence of venous thromboembolism [9]. However, it is not clear 
whether aspirin diminishes PE by regulating the expressions of FKN. Therefore, the aim of this study was to evaluate the alteration of $F K N$ in rats subjected to $P E$, and the effect of aspirin on FKN expression and lung morphological alterations in PE.

\section{EXPERIMENTAL}

\section{Animals}

Male Sprague Dawley (SD) rats $(262.63 \pm 50.59$ g) were purchased from Jiangnan Experimental Animal Center in Huishan, Wuxi, with the certificate no. SCXK (Su) 2009-0005. The experiments were reviewed and approved by the Animal Care and Use Committee of Zhejiang Chinese Medical University, China (no. 20120793). The animals were handled according to standard protocols for the use of laboratory animals [10].

\section{Reagents}

Aspirin was purchased from Shijiazhuang Conic Pharmaceutical Co, Ltd (Shijiazhuang, China). Enzyme-linked immunosorbent assays (ELISA) kits for rat tumor necrosis factor $\alpha$ (TNF- $\alpha$ ), interleukin-1 $(\mathrm{IL}-1 \beta)$, interleukin-8 (IL-8), and FKN were purchased from Morrison Shanghai biotechnology Co, Ltd (Shanghai, China). TRizol Reagents and Platinum SYBR Green qPCR SuperMix UDG were purchased from Invitrogen Corporation (Camarillo, CA, USA). Reverse transcriptase kits (RevertAid First Strand cDNA synthesis Kit) were purchased from Fermentas Company, Canada. Recombinant DNase I (RNase-free) was purchased from Dalian TaKaRa Biotechnology Co, Ltd, China. Unless indicated otherwise, all other chemicals were of analytical purity. OD values were measured by the Molecular Devices Spectra max Plus 384. Quantitative polymerase chain reaction (qPCR) was run in a Bio-Rad MJ Mini Opticon Real-Time PCR system and analyzed by Bio-Rad CFX Manager.

\section{Preparation of PE model}

The rat PE model was established by injection of self-embolus into the right jugular vein. In essence, the rat blood was drawn from the orbital venous and placed in sterile bottles for $4 \mathrm{~h}$ to form a dense embolus, which was then trimmed into $2 \mathrm{~mm}^{3}$ pieces and suspended in saline solution. After the rat was anesthetized with chloral hydrate $(400 \mathrm{mg} / \mathrm{kg}$, i.p.), the right jugular vein was isolated and $0.5 \mathrm{ml}$ embolus suspension (approximately 15 - 20 embolus) was quickly injected into the right jugular vein. The success of PE in the PE group was ascertained by respiratory manifestations (including accelerated and deepened breathing), and was confirmed by lung pathology. The histological feature of PE was alveolar hemorrhage and alveolar necrosis [11].

\section{Rat groups and treatment}

Sixty-four SD male rats were divided into four groups ( $n=16)$ according the random allocation table of SPSS software: control group (control), sham operation operation group, PE model group (PE) and $\mathrm{PE}+$ aspirin group (PE + aspirin). All rats were orally administered with aspirin $(300 \mathrm{mg} / \mathrm{kg})$ or the same volume of saline $(1 \mathrm{ml} / 100 \mathrm{~g}$ ) on day 1 and $40 \mathrm{~min}$ before PE surgery. The rats in control group were not injected with substance. The rats in Sham operation group received $0.5 \mathrm{ml}$ normal saline injection into the right jugular vein instead of selfembolus. The rats in PE and $\mathrm{PE}+$ aspirin group received $0.5 \mathrm{ml}$ self-embolus and also orally administered daily with aspirin $(300 \mathrm{mg} / \mathrm{kg})$ at the 6 th hour following embolism. The rats in control, Sham operation and PE groups were orally administered with the same volume of saline daily. At 4th and 72nd hour following embolism, eight rats in each group were sacrificed under anesthesia and the blood and lung tissues harvested.

\section{Measurement of serum cytokines}

At 4th and 72nd hour following embolism, the rats were anesthetized with chloral hydrate (400 $\mathrm{mg} / \mathrm{kg}$ ), blood collected from the abdominal aorta, allowed to settle for $15 \mathrm{~min}$, centrifuged (3000 rpm, $10 \mathrm{~min}, 4^{\circ} \mathrm{C}$ ), and the supernatant was used for FKN, IL-8, TNF- $\alpha$, and IL-1 $\beta$ measurements with the double-antibody sandwich ABC-ELISA method.

\section{Measurement of cytokine expression in lung tissues}

At $4 \mathrm{~h}$ and $72 \mathrm{~h}$ following the embolism, rats were sacrificed under anesthesia and the lung tissues were harvested and stored at $-70^{\circ} \mathrm{C}$. The frozen lung tissue was pulverized to a powder. Total RNA was extracted using Trizol. The mRNA expressions of FKN, TNF- $\alpha$, and IL-1 $\beta$ in lung tissues were determined with $\mathrm{qPCR}$. The RT reaction was amplified using TaqDNA polymerase and primers to murine FKN, TNF- $\alpha$, and IL-1 $\beta$ cDNA as shown in Table 1. 
Table 1: RT-PCR primers

\begin{tabular}{lccc}
\hline Gene name & Gene ID & \multicolumn{1}{c}{ Primer } & Length (bp) \\
\hline \multirow{2}{*}{ GAPDH } & 2597 & 5'-CAAGGTCATCCATGACAACTTTG-3' \\
& & 5'-GTCCACCACCCTGTTGCTGTAG-3 & 496 \\
FKN & 5'-GGTGGCAAGTTTGAGAAGCG-3' & \\
& & 5'-CCTGGGAAATAGCAGTCGGTT-3' & 142 \\
TNF- $\alpha$ & 24835 & 5'-ACAGAAAGCATGATCCGAGATG-3' & \\
& & 5'-TTCAGTAGACAGAAGAGCGTGGTG-3' & 149 \\
IL-1 3 & 5'-GAGGCTGACAGACCCCAAAAG-3' & \\
& 24494 & 5'-TCCACGGGCAAGACATAGGTAG-3' & 362 \\
\hline
\end{tabular}

Measurement of pathological changes in lung tissues

The rat lung was isolated and the wet weight index of lung was calculated using the following formula: the wet weight index of lung = lung weight / body weight $\times 100 \%$ [12]. The lung tissue was fixed for $24 \mathrm{~h}$ in $10 \%$ formalin solution, paraffin- embedded, and hematoxylineosinstaining (HE)-stained.

\section{Statistical analysis}

Values are expressed as mean \pm standard deviation (SD). Statistical analysis was performed using one-way ANOVA to compare variables between groups, while linear regression was used to analyze the relevance between serum FKN and TNF- $\alpha$, IL-8 as well as IL-1 $\beta$ following embolism. Statistical significant of differences was examined by paired-samples test in the corresponding group between 4 and $72 \mathrm{~h}$ following embolism. $p<0.05$ was considered statistically significant. Statistical analysis was performed using SPSS software (version 17.0, SPSS Inc, USA).

\section{RESULTS}

\section{Serum levels of FKN, IL-8, TNF- $\alpha$ and IL-1 $\beta$}

As shown in Fig 1, at $4 \mathrm{~h}$ following the embolism, the serum levels of FKN in PE group were significantly increased compared with that in the sham operation operation group $(p<0.05)$, and decreased after treatment with aspirin $(p<0.05)$ (Fig 1A). The serum levels of IL-8 in PE group were higher than sham operation operation group ( $p<0.05$ ) (Fig 1B), and reversed by treatment with aspirin at $4 \mathrm{~h}$ following the embolism. The serum levels of FKN, IL-8, TNF- $\alpha$ and IL-1 $\beta$ did not differ between control and sham operation group. TNF-a levels in PE group were significantly decreased relative to the aspirin treatment group ( $p<0.05$ ) (Fig 1C). There were no significant differences of the serum IL-1 $\beta$ in all groups (Fig 1 D). At $72 \mathrm{~h}$ following the embolism, the serum FKN, IL-8, TNF- $\alpha$ and IL-1 $\beta$ were all markedly increased in the PE group compared with that in the sham operation group $(p<0.05)$, and decreased after treatment with aspirin $(p<0.05)$. The serum cytokines measured did not differ between control and sham operation operation. Compared with the corresponding group at $4 \mathrm{~h}$ following the embolism, FKN levels in PE group and PE + aspirin group at $72 \mathrm{~h}$ were significantly increased $(p<0.01)$; TNF- $\alpha$ in the PE group were higher at $72 \mathrm{~h}$ following $(p<0.01)$, but in $\mathrm{PE}+$ aspirin group they were decreased significantly $(p<$ $0.01)$. The IL-1 $\beta$ in the PE group at $72 \mathrm{~h}$ following the embolism was significantly increased $(p<$ 0.05) (Fig 1).

\section{Linear regression}

Through the analysis of the correlation between the serum FKN and TNF- $\alpha$, IL- 8 as well as the $\mathrm{IL}-1 \beta$ following the embolism, we found that the serum FKN had nothing to do with IL-1 $\beta$, but was only related to IL-8 and TNF- $\alpha$. This is evident from Eqs 1 and 2.

$$
\begin{aligned}
& \text { FKN }=1673.40+1.95 \times \text { IL-8 } \ldots \ldots \ldots \ldots \ldots . . \\
& (r=0.61, F=11.957, p<0.01) \\
& \text { FKN }=1927.50+3.89 \times \text { TNF- } \alpha \ldots \ldots \ldots \ldots . . \\
& (r=0.61, F=11.99, p<0.01, \text { see Fig } 2)
\end{aligned}
$$

By analysis of the correlation between serum FKN, and TNF- $\alpha, I L-8$ and IL-1 $\beta$ following the embolism, it was observed that serum FKN had no link with $\mathrm{IL}-1 \beta$, but was only related to $\mathrm{IL}-8$ and TNF- $\alpha$. 

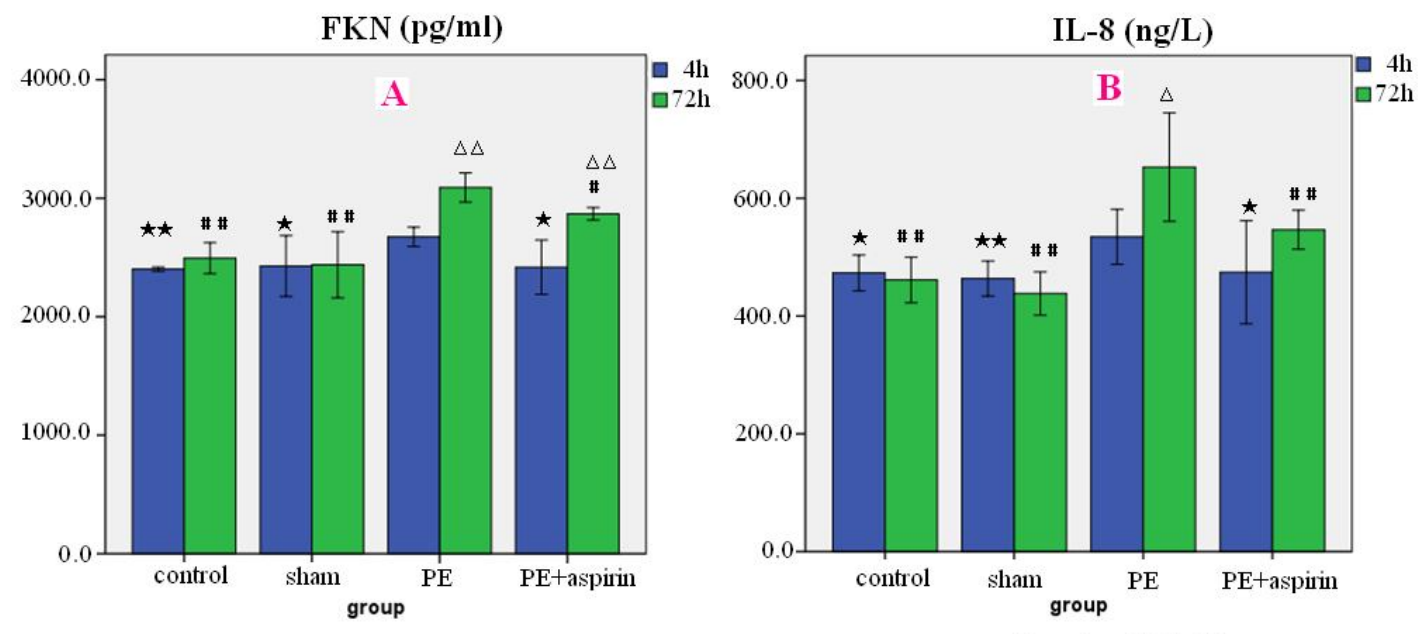

Error bar: $95 \% \mathrm{CI}$
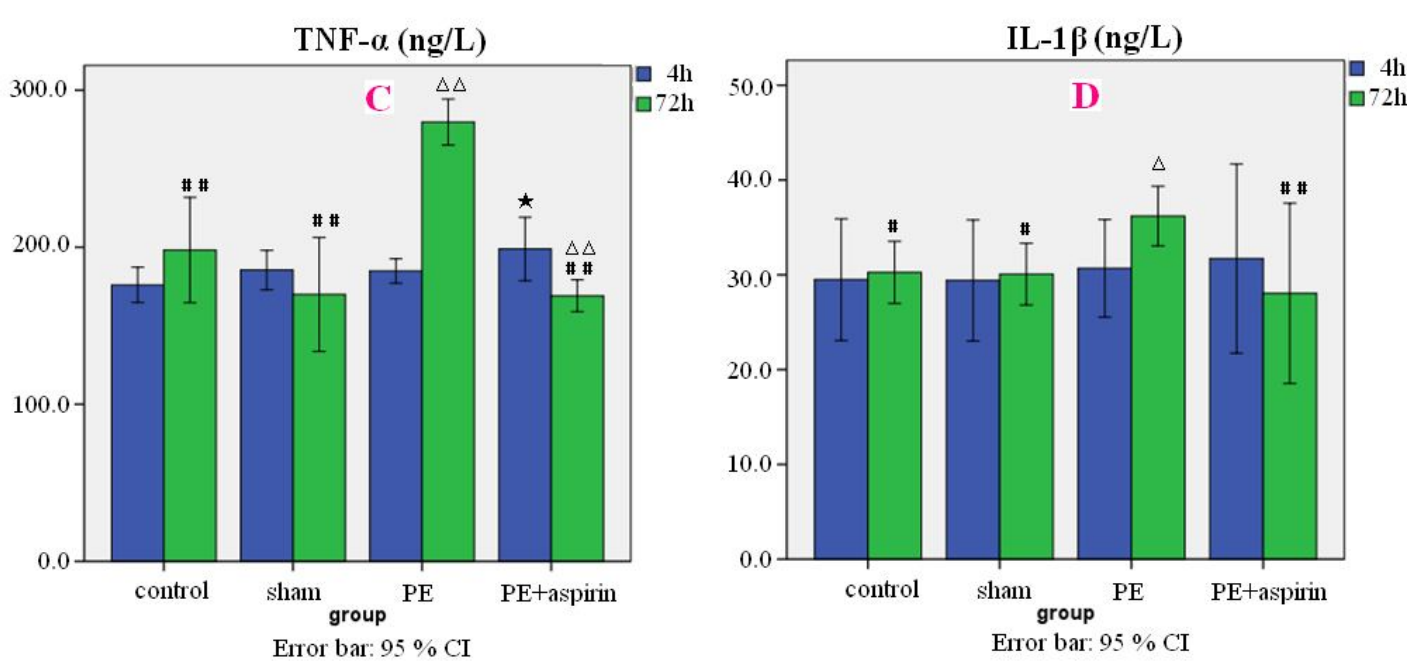

Figure 1: Comparison of the serum FKN, IL-8, TNF- $\alpha$ and IL-1 $\beta$ in four groups at $4 \mathrm{~h}$ and $72 \mathrm{~h}$ following embolism; compared with PE group at $4 \mathrm{~h}:{ }^{\star} p<0.05,{ }^{\star}{ }^{\star} p<0.01$; compared with PE group at $72 \mathrm{~h}:{ }^{\sharp} p<0.05,{ }^{\# \#} p<0.01$; compared with the corresponding group at $4 \mathrm{~h}$ following embolism: $\Delta p<0.05, \Delta \Delta p<0.01$
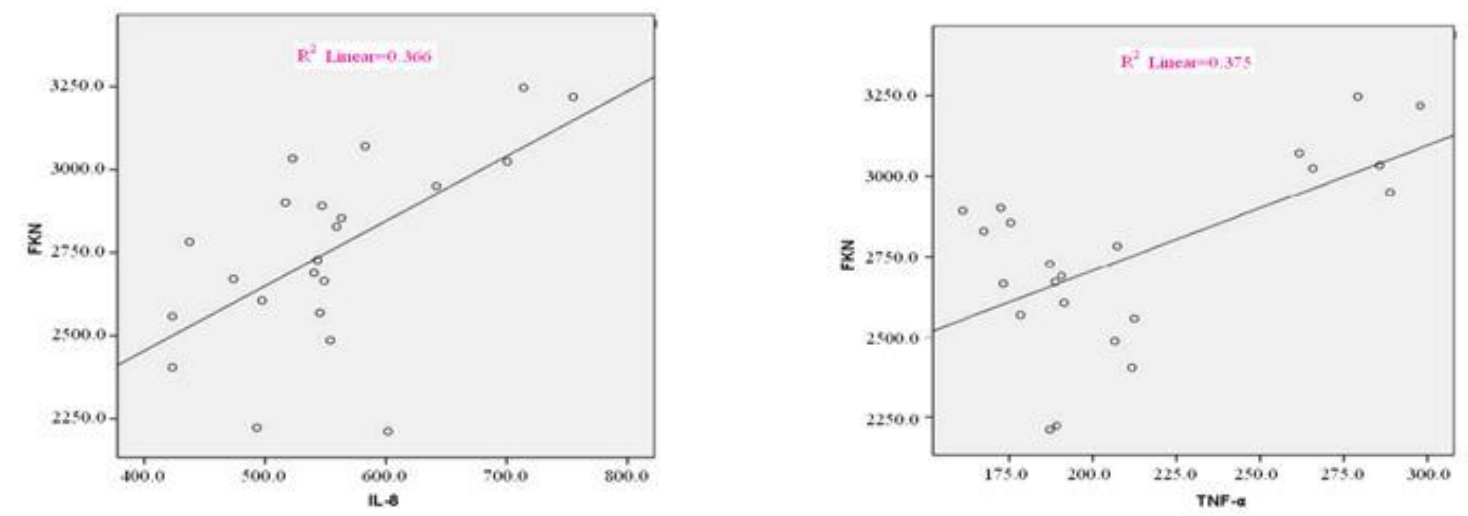

Figure 2: Linear regression analysis

mRNA expression of FKN, TNF- $\alpha$ and IL-1 $\beta$ in lung tissues

At 4 and $72 \mathrm{~h}$ following embolism, the mRNA expression of FKN, TNF- $\alpha$ and IL-1 $\beta$ were all significantly increased $(p<0.01)$ in the PE group compared with that in the sham operation group (Fig 3), but decreased after treatment with aspirin $(p<0.01)$. All the mRNA expression of cytokines measured did not differ between control and 
sham operation operation. The mRNA expression of FKN and TNF- $\alpha$ in PE group at $72 \mathrm{~h}$ following the embolism were significantly higher than the corresponding group at $4 \mathrm{~h}$ ( $p<$ $0.05)$, and there were no difference in the other groups (Fig 3).

\section{Wet weight index of lung and rat lung pathology}

As shown in Fig 4, at $72 \mathrm{~h}$ following the embolism, the wet weight index of lung was markedly increased in the PE group compared with that in the control group ( $p<0.05)$, but decreased significantly after treatment with aspirin $(p<0.01)$. There were no significant differences of the wet weight index of lung between the control, sham operation, PE group at $4 \mathrm{~h}$ following the embolism, but increased after treatment with aspirin $(p<0.05)$. Similarly, the wet weight index of lung did not differ between control and sham operation. At $72 \mathrm{~h}$ following the embolism, the wet weight index of lung was markedly lower than in the corresponding group at $4 \mathrm{~h}$ after treatment with aspirin $(p<0.01)$.

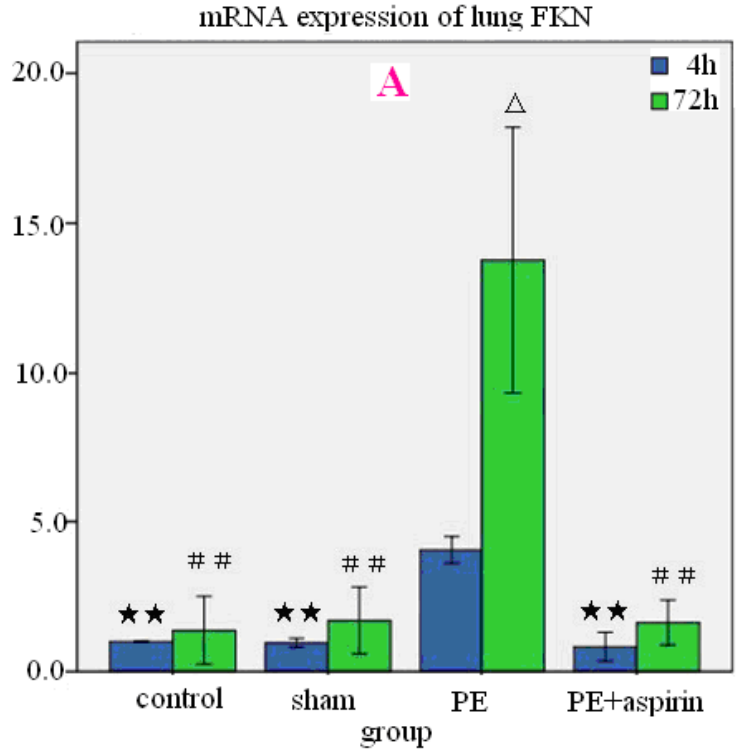

Error bars: + $+-2 \mathrm{SE}$

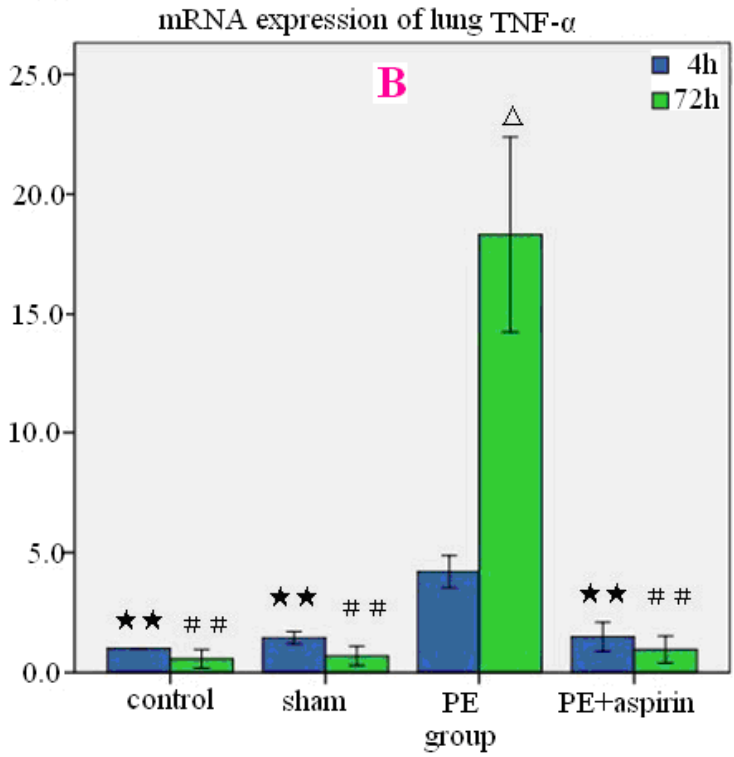

Error bars: $+/-2 \mathrm{SE}$

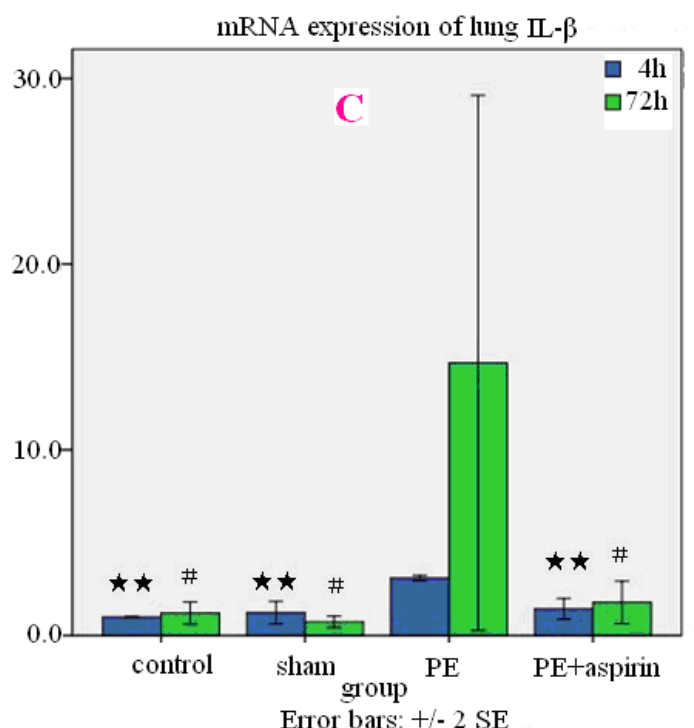

Figure 3: FKN, TNF- $\alpha$, IL-1 $\beta$ levels of lung tissues for four groups at 4 and $72 \mathrm{~h}$ following the embolism. Compared with PE group at $4 \mathrm{~h}:{ }^{\star} p<0.05,{ }^{\star \star} p<0.01$; compared with PE group at $72 \mathrm{~h}:{ }^{*} p<0.05,{ }^{\# \#} p<0.01$; Compared with the corresponding group at $4 \mathrm{~h}$ following the embolism: $\Delta p<0.05, \Delta \Delta p<0.01$ 


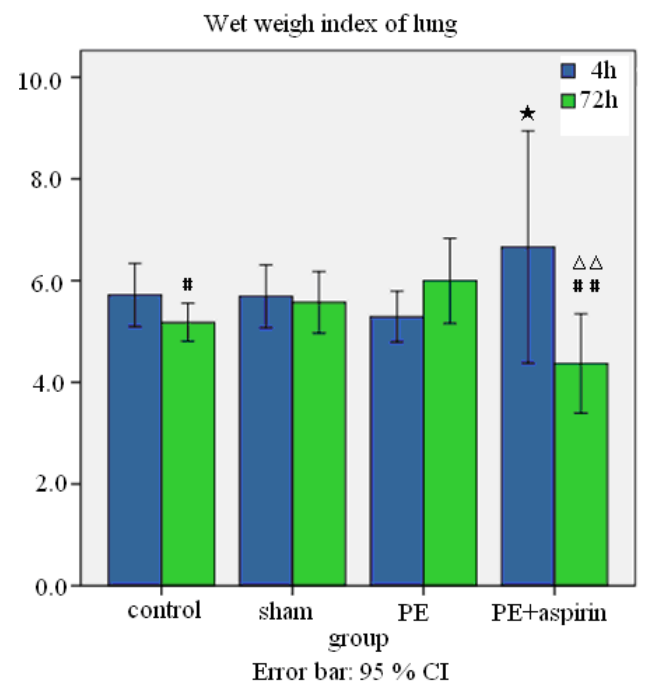

Figure 4: Wet weight index of lung for the four groups at 4 and $72 \mathrm{~h}$ following the embolism; compared with PE group at $4 \mathrm{~h}:{ }^{\star} p<0.05,{ }^{\star \star} p<0.01$; compared with PE group at $72 \mathrm{~h}:{ }^{\#} p<0.05,{ }^{\# \#} p<0.01$; compared with the corresponding group at $4 \mathrm{~h}$ following embolism: $\Delta p$ $<0.05, \Delta \Delta p<0.01$

Lung pathological examination was done in a total of 64 rats in 4 groups on two time points: at $4 \mathrm{~h}$ and $72 \mathrm{~h}$ (32 rats each) following embolism. At $4 \mathrm{~h}$ following embolism, the alveolar wall vessels was dilated and congested, with accompanying mild edema and inflammatory cell infiltration in PE group, while aspirin treatment attenuated these pathological changes induced by PE (Fig 5a, b, c and d). At $72 \mathrm{~h}$ following embolism, the alveolar wall vessels were markedly expanded and congested, but this was obviously reduced by aspirin (Fig $5 e, f$ and $h$ ).

\section{DISCUSSION}

Pulmonary embolism is the third most common cause of death from cardiovascular disease after heart attack and stroke. Venous thromboembolism and atherothrombosis share common risk factors and the common pathophysiological characteristics of inflammation, hypercoagulability, and endothelial injury [3]. Previous studies suggest that the adhesion between endothelial cells, platelet and leukocyte is involved in PE, and the inflammatory response induced by $P E$ further injuries the lung [13]. FKN together with its receptor on the endothelial cells is potent enough to capture the white blood cells to adhere closely to vascular endothelium even in the high blood flow [14]. When the aorta is full of inflammatory cells gathered by $\mathrm{FKN}$, it will play a role in the pathogenesis of some diseases, such as acute lung injury, pulmonary hypertension [15], and ischemic stroke [16].

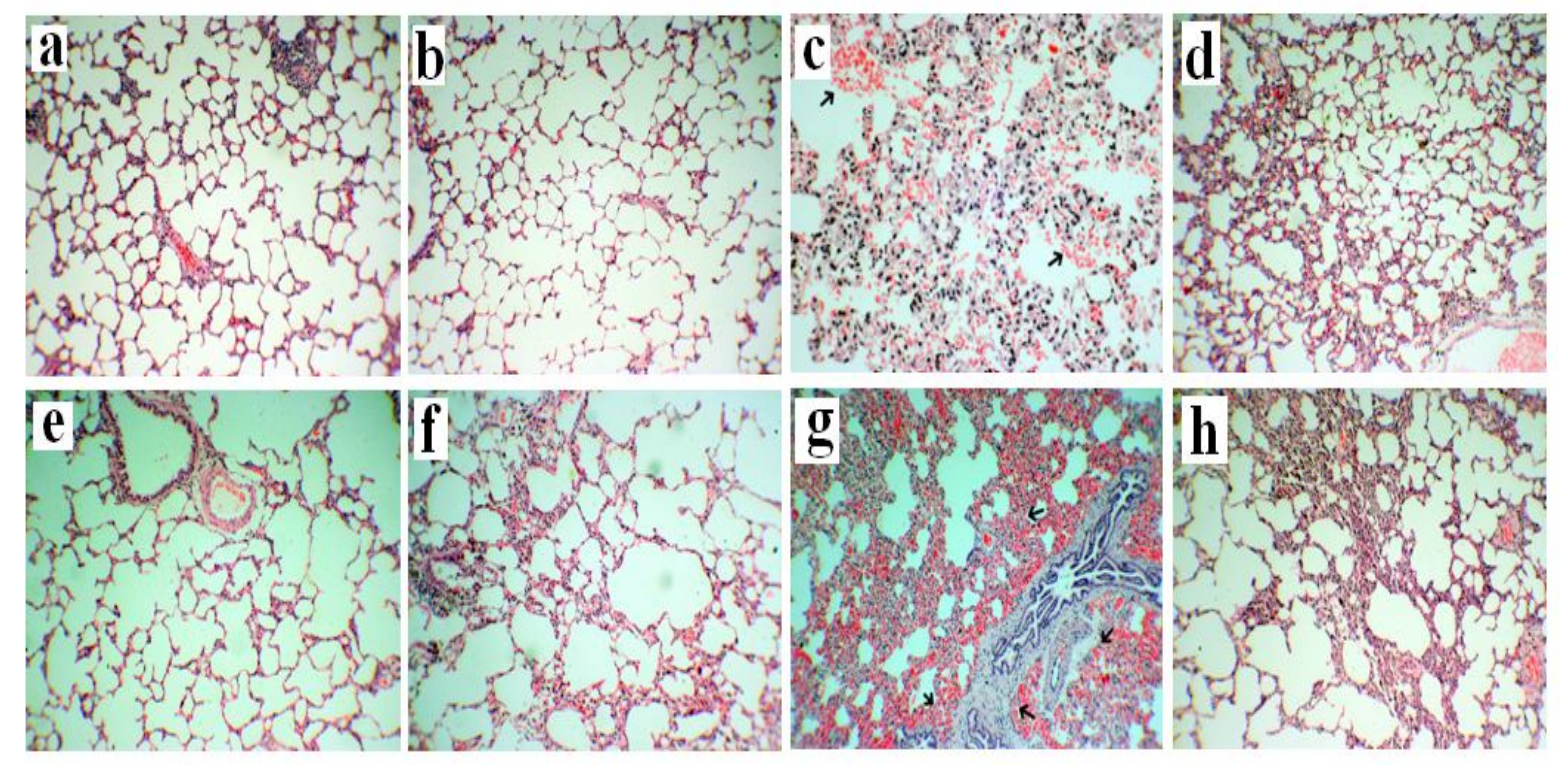

Figure 5: HE staining of the rat lung at $4 \mathrm{~h}$ and $72 \mathrm{~h}$ following the embolism $(\times 100) .4 \mathrm{~h}$ : control (a), sham operation (b), PE (c), PE + asprin (d); 72 h: control (e), sham operation (f), PE (g), PE + asprin (h). At 72 h following the embolism, the alveolar wall vessels was markedly expanded and congested, but these were reduced by aspirin 
However, to the best of our knowledge, there are no reports on the relationship between FKN and PE.

Our previous experiments have found that at the two time points (4 and $72 \mathrm{~h}$ ) following embolism, reflected PE characteristics [7]. In order to reduce the number of mice used we did not go beyond these time points. In this study, the lung pathological examination of the rats at $4 \mathrm{~h}$ following embolism showed that aspirin attenuated the pathological injuries of the lung induced by PE. At $72 \mathrm{~h}$ following embolism, the extent of lung congestion was markedly reduced by aspirin application, and the number of rats with infarction also decreased from 25 to $12.5 \%$. These results suggest that prophylactic use of aspirin might reduce the mortality induced by PE in rats by attenuating lung pathological damage. There was no difference between control and sham operation groups at $4 \mathrm{~h}$ and $72 \mathrm{~h}$ following embolism, indicating that sham operation had no effect on the lung morphology.

These results suggest that aspirin is effective in decreasing PE-induced FKN. At $72 \mathrm{~h}$ following embolism, serum FKN, IL-8, TNF- $\alpha$ and IL-1 $\beta$ in the PE group all significantly increased but aspirin attenuated these increases, indicating that these four cytokines might be closely related to advanced PE, and aspirin may diminish advanced $P E$-induced lung injuries by decreasing serum FKN, IL-8, TNF- $\alpha$ and IL-1 $\beta$. This study also found that at 4 and $72 \mathrm{~h}$ following embolism, mRNA expressions of FKN, TNF- $\alpha$ and IL-1 $\beta$ in lung tissues significantly increased. The increases were reversed by aspirin, suggesting that aspirin can inhibit lung inflammation. These results agree with the report that aspirin can inhibit the proinflammatory cytokines (TNF- $\alpha$, IL-1 $\beta$, IL-8) of lung [17]. Our previous study found that TNF- $\alpha$ level of 0.5 $\mathrm{ng} / \mathrm{ml}$ significantly stimulates expression of FKN mRNA and also protein expression in HUVECs using Western-blot technique [6]. Harrison et al [18] also reported that IL-1 or TNF- $\alpha$ stimulated FKN expression in endothelial cells. In addition, type I IFN induces CX3CL1 secretion from human pulmonary arterial-endothelial cells (HPAEC) but this can be prevented by Janus protein tyrosine kinase (JAK) inhibitor [19]. Based on linear regression data, serum FKN has no correlation with IL-1 $\beta$ after embolism, but has a moderate correlation with IL-8 and TNF- $\alpha$. This suggests that serum IL- 8 and TNF- $\alpha$ stimulates the secretion of FKN after embolism, and that the inhibition of serum FKN by aspirin is linked to the reduction in IL-8 and TNF- $\alpha$.

\section{CONCLUSION}

This study indicates that aspirin has protective effects against PE-induced lung injuries. Furthermore, the mechanisms of the protective effects of aspirin might be mediated by suppression of the expressions of IL-8, TNF- $\alpha$, IL-1 $\beta$ and fractalkine.

\section{ACKNOWLEDGEMENT}

This study was funded by Zhejiang Provincial Natural Science Foundation of China (Grant nos. Y207052 and LY12H29005).

\section{REFERENCES}

1. Kearon C. Natural history of venous thrombo-embolism. Circulation 2003; 107: I 22-30.

2. Wrobel JP, Thompson BR, Williams TJ. Mechanisms of pulmonary hypertension in chronic obstructive pulmonary disease: A pathophysiologic review. J Heart Lung Transplant 2012; 31: 557-564.

3. Goldhaber SZ, Bounameaux H. Pulmonary embolism and deep vein thrombosis. Lancet 2012; 379:1835-1846.

4. Bazan JF, Bacon KB, Hardiman G. A new class of membrane-bound chemokine with a CX3C motif. Nature 1997; 385: 640-644.

5. White GE, Greaves DR. Fractalkine: A survivor's guide: chemokines as antiapoptotic mediators. Arterioscler Thromb Vasc Biol 2012; 32: 589-594.

6. Wang LC, Jiang HF, Zhu DX, Wei KM. Intervention effect of curcumin on FKN expression in human umbilical vein endothelial cells induced by TNF- $\alpha$. Chin J Tradit Med Sci Technol. 2010; 17: 517-518, 524.

7. Cai B, Sun C, Wang LC, and Qian H: Curcumin improves the outcomes of acute pulmonary embolism in rats. Zhejiang Med J 2011; 33: 457-459.

8. Widmer BJ, Bassora R, Warrender WJ, Abboud JA: Thromboembolic events are uncommon after open treatment of proximal humerus fractures using aspirin and compression devices. Clin Orthop Relat Res 2011; 469: 3332-3336.

9. Becattini C, Agnelli G, and Schenone A: Aspirin for preventing the recurrence of venous thromboembolism. N. Engl. J. Med. 2012; 366: 19591967.

10. National Institute of Health, USA. Public health service policy on humane care and use of laboratory animals; 2002.

11. Chen HZ, Lin G.: Practice of Internal Medicine (13th Edition), Beijing, People's Health Publishing House 2009; 1859-1864.

12. Chen SB, Wang CY, Xu M: The effect of heart shock protein 70 on lung injury of rats with acute necrosis pancreatitis. J Chin Phys 2006; 8: 1593-1595. 
13. Smith A, Quarmby JW, Collins M, Lockhart SM, Burnand $K G$ : Changes in the levels of soluble adhesion molecules and coagulation factors in the patients with deep vein thrombosis. Thromb Hae most 1999; 82: 1593-1599.

14. Meyer dos Santos S, Klinkhardt U, Scholich K, Nelson K, Monsefi N, Deckmyn H: The CX3C chemokine fractalkine mediates platelet adhesion via the von Willebrand receptor glycoprotein Ib. Blood 2011; 117: 4999-4950.

15. Wang L, Wang G, Li TQ: Effect of Shenqi Fuzheng injection on fractalkine expression in lung tissue of rats with lipopolysaccharide-induced acute lung injury. Chin J Integr Trad Western Med 2007; 27: 5559.
16. Donohue MM, Cain K, Zierath D, Shibata D, Tanzi PM, Becker KJ: Higher plasma fractalkine is associated with better 6-month outcome from ischemic stroke. Stroke 2012; 43: 2300-2306.

17. Literat A, Su F, Norwicki M, Durand M, Ramanathan R, Jones CA: Regulation of pro-inflammatory cytokine expression by curcumin in hyaline membrance disease (HMD). Life Sci 2001; 70: 253-267.

18. Harrison JK, Jiang $Y$, Wees EA, Salafranca MN, Liang $H X$, Feng L: Inflammatory agents regulate in vivo expression of fractalkine in endothelial cells of the rat heart. J Leukoc Biol 1999; 66: 937-944.

19. Nakano M, Fujii $T$, Hashimoto M: Type I interferon induces CX3CL1 (fractalkine) and CCL5 (RANTES) production in human pulmonary vascular endothelial cells. Clin Exp Immunol 2012; 170: 94-100. 